\title{
Desconfianza, regímenes de verdad, conspiraciones y montajes en el contexto de la covid-19 en México
}

\section{Distrust, regimes of truth, conspiracies and assemblages in the context of Covid-19 in Mexico}

Andrea Murillo'

Centro de Estudios Antropológicos, El Colegio de Michoacán. Michoacán, México andreag.murillog@gmail.com

ORCID 0000-0002-8616-1520

Citar como: Murillo, A. (2020). Desconfianza, regímenes de verdad, conspiraciones y montajes en el contexto de la covid-19 en México. Desde el Sur, 12(2), pp. 547-571.

\section{RESUMEN}

Este ensayo examina la reproducción y circulación de videos, imágenes y memes para la construcción de regímenes de verdad en la esfera pública mexicana durante la pandemia de la covid-19. Desde marzo de 2020, fecha en que comenzó la circulación de información sobre contagios, muertes y repuntes de casos, medios digitales y sus plataformas de verificación de datos, familiares de personas fallecidas y hospitalizadas de covid-19 movilizaron en redes sociales videos e imágenes para evidenciar y comprobar lo que acontecía. Este cúmulo de información, sumada a los memes, generó un estado de ánimo de desconfianza en México ante las diferentes versiones compartidas. A partir de metodologías visuales, este ensayo examina cómo la imagen a través de las diferentes plataformas es reapropiada y recombinada con otros géneros discursivos en la pandemia de la covid-19 para la obtención de legitimidad y legibilidad. Dentro de la abundante información, la figura del subsecretario de salud, Hugo López-Gatell, especialista y encargado en dar a conocer a los mexicanos los detalles de la pandemia figuró de manera

1 Licenciada en Periodismo por la Universidad de Guadalajara y maestra en Antropología Social por El Colegio de Michoacán. Actualmente es candidata a doctora en Antropología Social por el Centro de Estudios Antropológicos de El Colegio de Michoacán, donde desarrolla una investigación sobre teorías extraterrestres y sentidos de lo extraño, prácticas materiales, procesos de desindustrialización y formación de contrapúblicos en Jalisco (México). 
considerable para mostrar índices de lo más próximo a la verdad. La imagen de López-Gatell como emblema de la verdad y de soberanía nacional se contrapuso al discurso contradictorio del actual presidente Andrés Manuel López Obrador.

\section{PALABRAS CLAVE}

México, estado de ánimo, medios audiovisuales, noticias falsas, manejo de las impresiones

\section{ABSTRACT}

This essay examines the reproduction and circulation of videos, images and memes for the construction of regimes of truth in the Mexican public sphere during the Covid-19 pandemic. Since March 2020, when the circulation of information on infection rates, deaths and spikes in cases began, through digital media and their data verification platforms, relatives of those deceased and hospitalized as a result of Covid- 19 have used videos and images on social networks to show and verify what is happening. This accumulation of information, added to memes, generated a mood of distrust in Mexico, in the face of the different versions being shared. Based on visual methodologies, this essay examines how, through different platforms, the image is re-appropriated and recombined with other discursive genres during the Covid-19 pandemic in order to achieve legitimacy and legibility. Amid an abundance of information, the figure of the undersecretary for health, Hugo López-Gatell, a specialist responsible for informing Mexicans regarding the details of the pandemic, figured prominently in efforts to disseminate figures approximating the truth. The image of López-Gatell as an emblem of truth and national sovereignty stood in contrast to the contradictory discourse of the current president, Andrés Manuel López Obrador.

\section{KEYWORDS}

Mexico, mood, visual media, "fake news», impression management

\section{Introducción}

Desde nuestros hogares y espacios cotidianos, a través del rumor y la imagen, hemos presenciado la pandemia de la covid-19. Con el uso de 
medios sociales de comunicación hemos experimentado el aislamiento y la pertenencia al momento actual de crisis sanitaria. Esto ha potencializado las prácticas visuales, y ha suscitado el compromiso activo por problematizar las ansiedades y sensibilidades en las esferas públicas.

En México han circulado imágenes y han sido retomadas por individuos y grupos sociales al punto de convertirlas en géneros discursivos ${ }^{2}$ más formalizados, como son las teorías de conspiración y noticias falsas. Ante esta circulación y remezcla de información, medios de comunicación y clase política destacaron una preocupación: verificar la información y no dudar de que el virus del SARS-CoV-2 exista. Tal fue la inquietud de líderes políticos y medios que declararon la segunda gran pandemia de México: «La pandemia de las noticias falsas» ${ }^{3}$.

Académicos de las humanidades, específicamente de la comunicación y la psicología, también se sumaron a esta preocupación. Y es que, desde esta mirada, la contingencia propició grandes índices de desinformación. La mucha información en torno al virus, en lugar de informar, trajo consecuencias graves, las cuales podrían causar la muerte. Esta insistente inquietud en contra de las noticias falsas o fake news en el momento actual me hizo reflexionar sobre las disputas por la verdad y la construcción de regímenes de verdad (Foucault, 1979) en la esfera pública mexicana a través de prácticas visuales. Sin pretender un enfoque fetichista hacia los medios audiovisuales y las imágenes, me gustaría preguntar sobre cómo la imagen a través de las diferentes plataformas es reapropiada y recombinada con otros géneros discursivos en la pandemia de la covid-19 para la obtención de legitimidad y legibilidad.

Las imágenes, los videos y los medios sociales de comunicación en esta pandemia han estructurado su orientación temporal hacia el futuro (Hirschkind, De Abreu y Caduff, 2017). Esta orientación tiene que ver con el

2 Por géneros discursivos me refiero al uso que Mijaíl Bajtín (1989) brinda al enunciado en el lenguaje. Las fuerzas centrípetas sirven para objetivar y centralizar la idea de lenguaje único; sin embargo, en este proceso interactúan fuerzas centrífugas de descentralización. De tal forma el lenguaje se estratifica a partir de grupos sociales, formando un plurilingüismo en la vida activa del lenguaje. Bajtín hace hincapié en que lo fundamental para no ver los grupos sociales coherentes y aislados es entender que «cada enunciado concreto del sujeto del habla representa el punto de aplicación tanto de fuerzas centrípetas como de las centrífugas» $(1989$, p. 90). Por tal, y sobre ello ahondaré más adelante, las «teorías de conspiración» y las «noticias falsas» están insertas en procesos de intertextualidad en lo que resalta una economía política por la regimentación de verdades para la obtención de visibilidad y presencia en la escena pública mexicana.

3 México no fue el único país en declarar la pandemia «de las noticias falsas» o «de los fake news». Incluso en la región latinoamericana se declaró el problema de la «infodemia», principalmente en países como el Perú, Argentina, Brasil, Colombia y Chile. Países como China, Estados Unidos, España, Indonesia e Inglaterra, entre muchos otros, también alzaron la mano en contra de las noticias falsas y la desinformación en esta pandemia. 
hecho de que el SARS-CoV-2 es un virus ${ }^{4}$ nuevo del cual se desconoce una vacuna, pero también por las emociones y sensibilidades que emergen a partir del uso de tecnologías visuales, como son la inquietud, la especulación y la desconfianza. Para este ensayo propongo interrogar la desconfianza como una emoción y un estado de ánimo. En esta contingencia emergió una necesidad moral de orden que objeta por la circulación de imágenes e información; esta posición prefiere lo «racional» y lo «verdadero» ante lo «irracional» y lo «falso». La desconfianza en México, considero, es histórica y está ligada al desencanto político, la desigualdad social referente al acceso diferenciado a las tecnologías de información, prácticas de corrupción e impunidad ante situaciones de violencia extrema y por el despliegue mediático sobre prácticas corruptas de medios de comunicación. El «ser desconfiado» está determinado por la coyuntura histórica y el ordenamiento social. $Y$ en este momento la desconfianza mexicana que convive con un virus reviste en sanitizar de información «falsa» el cuerpo social y construir lo «verdadero» con la evidencia de la imagen.

Además de distinguir la desconfianza como una emoción histórica, me gustaría considerar la desconfianza como parte de un estado de ánimo general. Tal distinción entre emoción y estado de ánimo me permite destacar un análisis diacrónico y sincrónico en el presente ensayo. La emoción potencializa observar los trazos históricos en las mediaciones y el estado de ánimo de desconfianza pondera en los ritmos y tonos de la circulación de información y en la reproductibilidad de las imágenes. Con ello podré analizar críticamente cómo las imágenes son retomadas para construir regímenes de verdad, o bien, junto con el humor, la forma en que estas potencializan una crítica a la gobernanza en México y la forma en que soportan prácticas de exclusión; y en la performance mediática, la forma en que conductores de televisión y funcionarios públicos manejan sus impresiones.

Partiendo de la idea de estado de ánimo de Jennifer D. Carlson y Kathleen Stewart (2014), quisiera centrarme en este estado ánimo de desconfianza que incluso yo he vivido. No quiero poner un orden ni tampoco desgastar los signos; más bien me adentro en este reto al escribir no «sobre» sino «con» el estado de ánimo de desconfianza que se vive, y en ello reconocer las dificultades de aproximarme a las realidades; sus

4 El virus del SARS-CoV-2 provoca la enfermedad respiratoria de la covid-19. Teniendo en cuenta esta distinción, y para hacer más ágil la lectura, aludiré al virus como covid-19. También al ser este hecho un problema de salud que engloba cuestiones económicas, políticas y culturales, además de que día a día hay un incremento en el número de casos y existe una propagación mundial de tal enfermedad, utilizo indistintamente contingencia, epidemia y pandemia. 
legibilidades, la simultaneidad y la diferencia que los sujetos sociales viven en constante desarrollo (Carlson y Stewart, 2014, p. 133). De igual manera, me gustaría retomar el concepto de regímenes de verdad desarrollado por Michael Foucault (1979) para afrontar las formas en que en México se producen los efectos de verdad, pero, sobre todo -e interrogando a Foucault-, si en lugar de pensar que la verdad en sí es poder, se puede reflexionar en los regímenes a través de los cuales medios audiovisuales, medios digitales, memes, videos y la clase política hacen visibles las verdades para la obtención de poder.

En la primera parte de este texto analizo el video «Remedios FALSOS contra el Coronavirus (parte 2)» publicado por El Sabueso, plataforma de verificación de datos del medio digital Animal Político. En él observo cómo son construidos los montajes desde los medios de comunicación digitales, y las estrategias que utilizan para legitimar su discurso visual. En la segunda parte analizo un caso tan sonado en México como fue «el robo del líquido de las rodillas por personal médico». A partir de videos, memes y notas periodísticas, analizo las formas en que el caso fue compartido y movilizado. Para este apartado me interesa explorar la circulación del meme, su relación con el humor y las exclusiones que destaca. En la tercera y última parte analizo la performatividad entre Hugo López-Gatell, el subsecretario de Salud, y Javier Alatorre, conductor de noticias del canal televisivo TV Azteca. López-Gatell, por su empatía con la prensa, fue el personaje más difundido en esta pandemia, pero también el más confrontado por medios hegemónicos y por gobernadores de oposición en el actual gobierno de López Obrador. La puesta en escena de López-Gatell y Javier Alatorre es clave para analizar la conformación del manejo soberano de las impresiones dentro de la esfera pública en México.

\section{Montajes}

El periodismo digital y la implementación de las tecnologías de información y comunicación (TIC) digitales en México requieren de una mirada histórica y contextual. El traslado del contenido noticioso a los marcos digitales en México está inaugurado por las estrategias comunicativas que movimientos indígenas como el Ejercito Zapatista de Liberación Nacional (EZLN), que desde 1994 ha implementado en blogs y plataformas digitales (Reguillo, 2020). Por otra parte, el periodismo digital en México ha tenido que pensarse como una forma que surge entre las «lógicas» comunicativas del crimen organizado y como respuesta de ciudadanos y periodistas ante la nula protección e intervención del Estado mexicano (Reguillo, 2011). Tal desprotección ha configurado formas de organización política diferentes al sistema de partidos, como son los casos de Ostula y 
Cherán en el estado de Michoacán. Por otra parte, la violencia criminal en México en la era digital también ha conformado tipos de ciudadanía neoliberal, al construir imaginarios de «protección propia» por parte de campesinos, líderes campesinos y medios de comunicación que sirven como agentes de mediación entre agentes estatales y agentes de la empresa privada para la no intervención en zonas lideradas por los carteles mexicanos (Zamorano, 2018).

Desde un marco mundial, el reconocimiento de las TIC digitales ha tenido distintos hitos históricos. Dominic Boyer (2010) encuentra que en países como Estados Unidos e Inglaterra el reconocimiento se remonta a 2004 y 2005 , cuando hubo un aumento en publicidad por internet combinada con la migración de audiencias, principalmente audiencias jóvenes a plataformas digitales. Anteriormente a estos años, en las décadas de 1980 y 1990, en el periodo de posguerra, los nacionalismos, en alianza con el gobierno keynesiano, proyectaron un sentido sistémico de límite nacional dentro del cual los ciudadanos individuales fueron vistos como elementos móviles, circulantes y productivos. Otro hito data de los años 40 y 50 en Estados Unidos, de la mano de antropólogas y antropólogos que emprendieron un compromiso con la naciente industria de la computación electrónica. Pero las raíces epistémicas de este movimiento se remontan aún más atrás, con la ciencia eléctrica y las ciencias sociales del siglo XIX (Boyer, 2010, pp. 77-78). Cuestión en la que resaltaría el concepto de realidad virtual acuñado por el filósofo francés Henri Bergson, con el que comienza una interesante reflexión sobre el movimiento de la imagen en el tiempo y el tiempo de la imagen en movimiento. $Y$ una conceptualización acerca de la realidad mediada por la tecnología (Deleuze, 1987).

Dentro del estudio de las TIC digitales ha surgido la atención y el análisis contemporáneo a la categoría de fake news o noticias falsas. Esta categoría obtuvo preponderancia a raíz de las elecciones presidenciales de Estados Unidos en 2016. El entonces candidato a la presidencia de Estados Unidos, Donald Trump, explotó las métricas de veracidad a partir del tuit para desacreditar «lo falso» de lo que él y sus seguidores marcaban como verdadero, situación que fundó un pánico moral en la sociedad estadounidense (Graan, 2018). A ello se aúna que en su elección incorporó y legitimó el discurso de la conspiración, utilizando tácticas de conmoción y asombro valorizadas a partir de la guerra mundial contra el terrorismo (Johnson, 2018). Por otra parte, las teorías de conspiración en Estados Unidos han tenido otras lecturas, vistas desde grupos sociales en diferente jerarquía social. A través de la práctica de construir teorías de conspiración, estas personas imaginan otros panoramas sociales donde también resuena intensamente el poder (Lepselter, 2016). En América Latina, principalmente 
en Venezuela, las narrativas de conspiración han sido estrategias para cuestionar la forma en que se producen dominios y distinciones de clase, raza y género (Briggs, 2004). De esa manera, las noticias falsas y las teorías de conspiración son tipos de informaciones que se distancian o se revelan ante un otro. La distinción de lo falso ante lo verdadero revela analizar cómo subyace lo «verdadero», y cómo este elemento después podría ser leído y retomado como «falso» por otros sujetos con intereses políticos particulares. Así, los regímenes de verdad son procesos inacabados que tanto individuos como grupos sociales realizan para crear el valor de verdad en un terreno políticamente mediado. En estos procesos convergen formas y texturas, las cuales pueden caracterizarse como montajes. En la idea de montaje prima el significado de lo falso o ilegítimo; para este caso, quisiera ver el montaje como un proceso textual y visual por el cual se legibilizan los contenidos.

$* * *$

Animal Político es un medio periodístico digital que surgió en 2010 como una propuesta para desafiar el monopolio mediático en México. Su arribo a la esfera pública mexicana estuvo emparejado junto con otro medio, Sinembargo.mx, de características similares. Ambas presencias parten junto a la oleada de diferentes apropiaciones tecnológicas en los movimientos sociales contra los gobiernos dictatoriales en África en la llamada Primavera Árabe, también en 2010. Estos movimientos harían eco en países de Europa y posteriormente en Estados Unidos y América Latina, cada uno con demandas distintas pero con la demanda en común por el libre acceso a la información como derecho social. En México se experimentaría con el movimiento liderado por jóvenes estudiantes conocido como \#YoSoy132 en 2012. Este movimiento surgió como respuesta a la victoria del entonces presidente electo priista Enrique Peña Nieto, impulsada en buena medida por el uso de trolls y bots en las redes sociales (Gallagher, 2017).

Animal Político, a través de su plataforma de verificación de datos $E I$ Sabueso, el 3 de abril subió a su página de Facebook un video titulado «Remedios FALSOS contra el Coronavirus (parte 2)» $»^{5}$. En este video Fernando

5 La primera parte del video fue titulada «Todas estas supuestas curas del coronavirus Covid-19 son FALSAS» (https://www.animalpolitico.com/video/todas-estas-supuestas-curasdel-coronavirus-covid-19-son-falsas/). Mi justificación al hacer análisis de los videos radica en que en ellos se muestra la información de una forma novedosa y creativa, quizás para hacer más lúdica la verificación con ciertos toques de humor e imagen en movimiento. 
Montes de Oca, editor de audiencias de Animal Político, expone ${ }^{6}$ dos remedios falsos contra la covid-19. En las primeras imágenes presenta el caso de dos soluciones para el virus, una con una secadora de pelo y otra con prácticas de vaporizaciones. Mientras Fernando sale a cuadro, a sus costados aparecen dos imágenes o stickers: una secadora y una persona haciendo vaporización. Después aparece el clip de una caricatura donde los personajes dicen la frase: «trust no one» (no confíe en nadie). Fernando, antes de comenzar a presentar los dos remedios, señala que son falsos y aparece el meme-video de Ben Affleck, actor de Hollywood, quien en una entrevista parece sumamente triste y con una mirada perdida. De fondo ante este meme-video aparece la canción «The sound of silence» de Simon \& Garfunkel. Un juego de imagen en movimiento y sonido que indica la caída de expectativas depositadas en la posible cura del coronavirus. Posteriormente, Fernando presenta a un otorrinolaringólogo de la ciudad de Monterrey, quien recomienda la «técnica de la secadora pelo», y de nuevo en pantalla aparecen dos stickers: una secadora y un virus, y un personaje de los Simpson diciendo: «Qué buena idea, cómo no se me había ocurrido!». Entonces entra en escena el video del otorrinolaringólogo - de quien protegen su identidad al difuminar su rostro y no decir su nombre- en su consultorio, o eso parece, por los diplomas que cuelgan tras de él, con un escritorio y una bata puesta ${ }^{7}$.

Este ensamble de elementos llama a considerar lo que Kathleen Stewart (2014) describe como montaje dentro de la teoría de la composición, una experiencia táctil de inmersión irremediablemente visual. El video como montaje muestra su potencialidad y estética a partir de un elemento clave: el humor. Las ligeras sonrisas son inevitables por todos los elementos visuales que construyen la narrativa, hacen sonreír mientras que la locución de Fernando, animada y lúdica, es fundamental para dirigirnos a su argumento: lo que dice el supuesto otorrinolaringólogo es falso y peligroso porque puede causar severas lesiones en la vía respiratoria. Incluso podría provocar la muerte por los altos grados de calor (56 grados) a los que las fosas nasales se expondrían. Y para respaldar su argumento, Fernando Montes de Oca cita al doctor Uritorruco García, internista e infectólogo del estado de Veracruz, de quien en el video agregan el audio

\footnotetext{
Además, analizo la segunda parte porque pone a debatir otros videos $-\mathrm{y}$ no solo texto o imagen- que agentes movilizaron en otra red social: YouTube. Mi interés por el video está en seguir la estrategia que este mismo medio implementó.

6 Previamente, Fernando Montes de Oca presentó un video donde muestra cómo saber si una imagen es falsa, manipulada o sacada de contexto. Para ello hace alusión a la «búsqueda inversa en Google» y otros sitios de verificación de imagen, tales como RevEye, donde se puede rastrear el origen de la imagen.

7 Ver el video completo en https://www.facebook.com/watch/?v=267228480965975
} 
de la llamada telefónica y una foto con una bata, en la cual se observa el logo de la Universidad Nacional Autónoma de México (UNAM). Además, para refutar la cura de la «técnica de la secadora de pelo», Fernando indica que el supuesto doctor no está certificado por el Consejo Mexicano de Otorrinolaringología, y también cita a la Organización Mundial de la Salud (OMS). Junto con imágenes animadas de una persona estornudando y la dispersión del virus en el aire, Fernando argumenta que las pruebas científicas indican que el virus de la covid-19 puede transmitirse en cualquier clima, sea caliente o frío.

La competencia de epistemologías es sugestiva. El rol de las tecnologías visuales para discernir qué es lo verdadero, aunado a cómo el cuerpo media en ello, es importante para observar la construcción de la objetividad en esta crisis sanitaria. Jeanette Edwards, Penny Harvey y Peter Wade (2010) argumentan lo importante que es atender no la imagen por sí misma, sino cómo esta es requerida para estabilizar y arreglar significados en las audiencias. El proceso de aprender a ver qué es lo correcto e ignorar lo demás, señalan los autores, involucra al espectador en una serie de decisiones sobre la relevancia de la información visual. Y para el campo científico como el artístico «la visión experta» depende de la discriminación que realiza el experto (2010, p. 21). Así entonces los diferentes imaginarios se unen de manera que estimulan nuevas relaciones entre el espectador y lo que observa: «Las imágenes actúan sobre nosotros a través de lo que hacen visibles, pero también a través de su capacidad de invocar lo que no se ve» (Edwards et al., 2010, p. 23). El video de El Sabueso actúa para resaltar lo correcto, opta por el argumento de un doctor que porta una bata con el logo de la máxima casa de estudios de México y descalifica la técnica del secado de pelo de un médico no avalado. Lo interesante aquí es observar la manera en que una epistemología cientificista resalta sobre la otra, y que, aunque una intente acercarse a la objetividad científica, y por ello porte elementos como una bata, narrar la técnica desde un consultorio y mostrar los diplomas, tal epistemología es colocada dentro del marco de la creencia. Muy ligada, diría yo, al campo de la superstición dentro de la esfera pública.

Para lo anterior, es importante considerar que la construcción de la racionalidad en la modernidad y en la esfera pública ha sido un largo y disputado proceso cultural e histórico donde disciplinas como la historia y categorías como progreso y desarrollo se han aparentado y alineado para contener el conocimiento hegemónico, esto en Europa entre los siglos XVIII y XIX (Koselleck, 1993). Jürgen Habermas (1981) identificó que, en el siglo XVIII en Europa, la tradición aristotélica de la moral en conexión con la naturaleza y la razón se extendieron a la esfera pública. Así, la opinión 
pública funcionaba como control social y una función legislativa: «Un conjunto de seres racionales que conjuntamente exigen leyes generales para su mantenimiento, conjunto respecto del cual todo el mundo se siente inclinado a excluirse» (1981, p. 142). Ahora, en medio de esta epidemia de salud en México las exigencias son hacia categorías de verificación, veracidad y razón.

El contenido anteriormente analizado es un video compartido por Animal Político a través de su plataforma de verificación de datos El Sabueso, que surgió en enero de 2015 para «contribuir a la vigilancia del debate público». Esta plataforma surgió en referencia a dos proyectos de verificación de datos internacionales. Uno es PolitiFact en Estados Unidos, que inició en 2007 a raíz del proceso electoral en Florida. PolitiFact, según su plataforma web, está conformado por periodistas y editores, quienes califican y escriben noticias de forma independiente, al utilizar su juicio sobre la información. El otro proyecto es Chequeado, creado en 2010 en Argentina, con el objetivo de luchar contra la desinformación.

Plataformas digitales como El Sabueso, PolitiFact y Chequeado son parte de un nuevo tiempo histórico en la era digital y en el periodismo digital que abre la reflexión sobre el carácter del verificado y la evidencia. Cada plataforma ha forjado este interés en sus respectivos países en tiempos escalonados ${ }^{8}$. Para el caso mexicano el interés por verificar la información data de los ataques cibernéticos que periodistas, académicos, grupos de familiares de personas desaparecidas y sociedad civil ha presenciado desde 2012 con los famosos «Peña Bots» para deslegitimar y desprestigiar en la escena pública a dichos actores ${ }^{9}$.

En esta pandemia ha crecido el interés por el verificado. Y mucho tiene que ver que la covid-19 sea un virus nuevo y las instancias médicas no posean referentes sobre él. Día a día construimos expectativas y especulaciones sobre las posibles curas (remedios y vacunas), y sobre los presentes y consecuentes estragos económicos que se avecinan, mediado todo esto por los montajes que individuos y medios digitales construyen. Los montajes son así estrategias proyectivas y de protección que plataformas como El Sabueso construyen para legibilizar y legitimar lenguajes visuales y salvaguardar la presencia de los medios digitales ante los otros, la sociedad de masas.

8 Además de El Sabueso, existe Verificado (https://verificado.com.mx/), que surge en 2018 con motivo de las elecciones presidenciales de México.

9 Para ver más sobre bots y trolls, revisar el trabajo de periodismo de investigación de Erin Gallagher: https://medium.com/@erin_gallagher/news-articles-about-bots-trolls-in-mexican-networks-7b1e551ef4a6 


\section{Conspiraciones}

Un caso que sonó bastante en esta pandemia, y del cual me enteré por la abundante circulación de memes y en una asesoría con Gabriela Zamorano, fue el robo del líquido de las rodillas. Al colocar en Google «líquido de rodillas + covid + Estado de México» el buscador me direccionó a una serie de notas periodísticas y videos de canales de noticias en YouTube. Al adentrarme en el contenido audiovisual observé que los videos expuestos en las notas provenían de familiares de personas internadas en el Hospital General Las Américas del Instituto de Salud del Estado de México (ISEM) en Ecatepec, Estado de México, en el centro del país.

En un video grabado por una mujer se escucha su llanto con gran desconsuelo y sufrimiento. La cámara hace movimientos desesperados por abrir paso y mostrarnos los cadáveres de personas fallecidas dentro de bolsas: «iMalditos! ¡Los están enfermando! ¡Estaban bien!», gritan los familiares ${ }^{10}$. En una videonota se muestra a la señora María, mamá de Alexis Guerrero, un joven fallecido por covid-19. La señora María argumenta con gran desesperación que su hijo hace apenas un día estaba bien, pero el día siguiente se encontró con la fatal noticia de que había fallecido. Las exigencias de María recaen en que a su hijo lo inyectaron y esto provocó su muerte. María, desesperada ante la cámara, menciona que la covid-19 no existe, y fueron los médicos del hospital quienes inyectaron a su hijo para matarlo ${ }^{11}$. En otra videonota se muestra el video grabado por un señor y la manera en que increpa y desafía a personal del hospital que, por su vestimenta, parece ser un camillero. La persona que graba se percibe molesta y le pregunta al camillero qué les dijo el gobierno: «¿Usted sabe que les están inyectando?». «No sé, voy llegando a trabajar», le responde el camillero. La persona que graba y sus acompañantes exigen al camillero una respuesta y este dice: «Medicamentos». «Sí, pero ¿cuáles?», le exigen ${ }^{12}$.

Días después de la circulación de estos videos, en la conferencia del 2 de mayo, el subsecretario de Salud, Hugo López-Gatell, mostró su indignación ante los hechos y señaló que el fenómeno de desconcierto y sorpresa de familiares en el Estado de México es por la propagación masiva de videos en redes. Pero sobre todo porque las personas no tienen una identificación clara de lo que significa la covid-19 grave, que se refiere a una neumonía y a que en pocas horas las personas pierden la vida. El subsecretario aludió a este hecho como «desinformación», pues las

10 Ver en https://www.youtube.com/watch?v=xIG2pYcMqUA (canal de RT en español). 11 Ver en https://www.youtube.com/watch?v=EkfqbQfolJw (canal de Noticias Telemundo). 12 Ver en https://www.youtube.com/watch?v=e7juYFetF0I\&t=37s (canal de Imagen Noticias). 
personas no están familiarizadas con la información y los significados de esta enfermedad ${ }^{13}$.

El tipo de exigencias que familiares intentan transmitir en sus videos forma parte de lo que Gabriela Zamorano (2020) nombra como archivos visuales digitales. Aquellos que permiten hacer reclamos específicos de ciudadanía y que tienen la posibilidad de nuevos reensambles. Estos archivos poseen la desconfianza y la ambigüedad como cualidades principales. Se insertan en el estado de ánimo actual y en la nombrada «era de la posverdad», la cual se caracteriza por la desinformación y la alfabetización que académicos y agentes estatales insisten en conferir a todo aquello que rebase el ideal de la esfera pública moderna. Esta es vista como racional y desencantada, valores que Max Weber y Jürgen Habermas mostraron en sus análisis de los Estados modernos europeos, que han formado un imaginario ilustrado moderno en países latinoamericanos. Pero lo revelador de estos archivos visuales digitales es que, además de argumentar su veracidad por el hecho de estar ahí, dentro del hospital, al mostrarnos las bolsas de los cadáveres, o indicarnos el rostro del personal médico, es que no están exentos de remontajes y de lo que Alex Fattal (2014) nombra como la circulación recombinante de videos. Para Fattal es necesario cuestionar la supuesta «apertura» y la circulación participativa en línea, al observar en estos ensamblajes prejuicios y prácticas violentas de exclusión.

Cuando revisé los videos identifiqué que en los diálogos de las personas que graban y de las personas que aparecen a cuadro, en ningún momento nombran «líquido de las rodillas». Hacen énfasis y cuestionan lo que a sus familiares les inyectan, pero no aluden a dicha sustancia. Posteriormente, también en YouTube, encontré una videonota de 2017 donde una mujer de nombre Lucina Rojas López, en la sección «Atención ciudadana» de una televisora local del estado de San Luis Potosí, denunció las negligencias médicas que vivió en el Hospital Central de su ciudad. Lucina cuenta que un practicante de ortopedia le extrajo el líquido sinovial de su rodilla izquierda. Y en lugar de tirarlo, lo guardó en el refrigerador. Ella observó el líquido amarillo con bolitas blancas que, como muchas personas le dijeron, vale miles de pesos en la industria farmacéutica ${ }^{14}$.

Los videos de los familiares fallecidos por covid-19 en el Hospital Las Américas y la escena de extracción del líquido de las rodillas de Lucina fueron reunidos a partir de la circulación de memes. En este apartado me interesa interrogar la circulación del meme, su relación con el humor y las

13 Ver en https://www.youtube.com/watch?v=Fr8VP_mMpPs (canal de Milenio).

14 Ver la nota completa en: https://www.youtube.com/watch?v=2dVDvdJ8FDE\&t=6s 
exclusiones que destaca. De nueva cuenta, ahondar en el origen de estos medios visuales y en quiénes los producen carece de explicación para este trabajo, no sin antes insistir en el montaje y en la composición de la desconfianza a partir de los medios visuales.

La escena de los familiares del Hospital Las Américas y de la señora Lucina han sido catalogadas por youtubers, periodistas y analistas como «conspiraciones absurdas», pues en algunos casos no creen en la existencia de la covid-19. Sin embargo, quizás más que indicarles a las personas que el virus existe, es necesario adentrarnos en su estado de ánimo, que ha sido construido por fallas y desencantos históricos con la clase política y con los procesos por encontrar justicia y verdad, al punto de buscar la verdad por fuera de los procesos legales (Piccato, 2017).

El meme es una tecnología visual en la que confluyen enunciados lingüísticos con lenguajes políticos y humorísticos. El meme tiene una cualidad intrínseca de anonimato que lo convierte en una fuente sumamente opuesta: desde prueba legítima hasta plena falsedad. Tal extremo potencializa la circulación del meme, es decir, lo convierte reproductible y en su reproducción revela prácticas de exclusión y jerarquías en los circuitos digitales. Estas prácticas bien pueden ser catalogadas como «desinformación» o «hedonismo» en las interacciones en línea. Sin embargo, considero que forman parte de un tropo visual de evidencia que alude a algo más que a su significado literal. El meme es parte de un tropo visual de evidencia ${ }^{15}$ en la trama agonística mexicana en busca de democracia, ciudadanía, rendición de cuentas por la violencia y la corrupción política.

Ecatepec de Morelos es un municipio del Estado de México ubicado en la frontera con la Ciudad de México. Ecatepec, junto con otros municipios del Estado de México como Nezahualcóyotl, Naucalpan, Cuautitlán Izcalli, Toluca y Lerma, se han acentuado en el imaginario social mexicano como «Mordor» o «Tierra negra», en alusión a la región ficticia creada por J. R. R. Tolkien en su novela El Señor de los Anillos ${ }^{16}$. Mordor en el relato literario es la fortaleza del mal y posee un aspecto montañoso, lúgubre e inhóspito. convenciones y giros en la trama. Digamos que los memes podrían pensarse como parte de un proceso intertextual centrado en la dialéctica de justicia y verdad en México.

16 Para leer más sobre este imaginario, ver https://www.vice.com/es/article/9abx38/demordor-a-mad-mex-una-cronica-del-estado-de-mexico y también https://medium.com/@ elmexiqueno/mexiquenses-de-mordor-la-ruta-incierta-y-salvaje-a-la-cdmx-bb243adc3a2d 


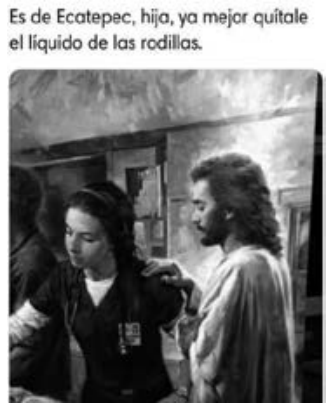

FIGURA 1. Imagen tomada de la página de Facebook The Sensei, es cuánto el 4 de mayo de 2020.

Esta identificación regional entre la zona conurbada del Estado de México con Mordor refiere a las situaciones de precariedad, inseguridad y violencia que se viven en aquella región.

La periodista Lydiette Carrión (2018), en su libro La fosa de agua. Desapariciones y feminicidios en el río de los Remedios, describe el hallazgo de 21 cuerpos, la mayoría de mujeres, en el río que cruza los municipios del Estado de México, uno de ellos Ecatepec. Carrión encuentra que en 2000 el gobernador del Estado de México, Arturo Montiel, y el Grupo Sadasi emprendieron un proyecto para construir 18000 viviendas de interés social de 65 metros cuadrados en el municipio de Tecámac. Este proceso de urbanización fue desarrollado en municipios como Ecatepec, en una apuesta por consolidar el sueño de los suburbios, al atraer a habitantes de diferentes alcaldías de la Ciudad de México y del mismo Estado de México para formar un patrimonio. La conformación de estos municipios en "ciudades dormitorio» ha sido parte de los cimientos del incremento de homicidios y feminicidios en esta zona, al ser Ecatepec el municipio que encabeza la cifra de feminicidios en el Estado de México y uno de los punteros en desapariciones de mujeres a nivel nacional ${ }^{17}$.

Todos estos marcadores regionales sirven como telón de fondo para argumentar que este tipo de memes refuerzan la representación del imaginario salvaje de Mordor como lugar «incivilizado», y exaltan un regionalismo que fragmenta aún más las divisiones entre Estado de México y Ciudad de México. Los recursos lingüísticos de «es» y «de» en el meme son índices que siguen una orientación espacial. Lejos de ser un discurso sin importancia, remiten al origen territorial de Ecatepec. Esta distinción espacial a través de la materialidad discursiva del meme apunta a dos

17 Ver en https://www.proceso.com.mx/nacional/estados/2020/11/13/por-violencia-degenero-exigen-renuncia-del-alcalde-de-ecatepec-del-fiscal-alejandro-gomez-252722.html 


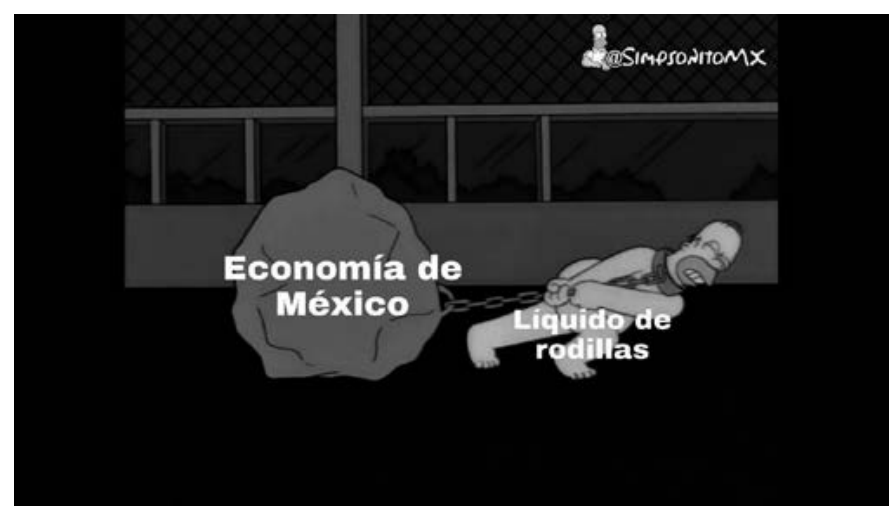

FIGURA 2. Imagen tomada del usuario de Instagram @SimpsonitoMX el 26 de julio de 2020, https:// www.instagram.com/p/B_yedigjpWA/

diferenciaciones, una de clase y otra de raza, ambas hilvanadas con el humor. Ambas discriminaciones son promovidas por este meme de forma sutil entre el texto y la compasión expresada por el toque de hombro de Jesús a la doctora. El racismo silencioso (De la Cadena, 2014) que emerge en el meme es a partir de la inferioridad que se presupone a Ecatepec como región de incivilización, atada a un supuesto evolucionista que privilegia la razón, si bien el humor es en sí una práctica moral y violenta en la que siempre habrá alguien que resulte afectado por la risa del otro. En este meme, el regionalismo que soporta exclusiones de clase y raza permite generar preguntas por tipos de violencia que se naturalizan en las interacciones digitales. Esto plantearía una necesidad de mayor investigación antropológica por los sentidos de región, diferenciación y exclusión a través de medios visuales en las interacciones en línea.

Entre los memes que observé circular resaltaba un «nosotros» nacional que encontraría su mejora económica a partir de un «ellos», el líquido de rodillas. Los memes montan imágenes de otros géneros; por ejemplo, caricaturas de los Simpson con textos sobre el tema en debate. En este meme Homero Simpson, con gran fuerza, jala de una cadena una enorme roca. En esta imagen converge la idea de castigo y sacrificio. Por una parte, la cadena simboliza el castigo, en referencia a las penas económicas y, por otra parte, el líquido de rodillas personalizado en Homero ejerce un sacrificio para mover la enorme y pesada economía de México. Esto en alusión a las crisis económicas derivadas de la pandemia, la falta de recursos que la administración de López Obrador ha decretado para la contingencia sanitaria, la reducción que ha hecho a distintas dependencias públicas, y los despidos por parte de la empresa privada, lo que ha desencadenado una pesada carga económica. 


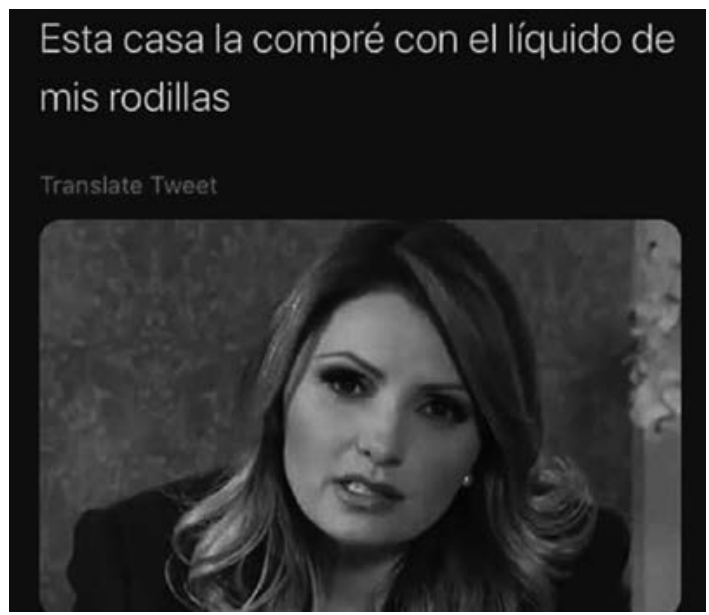

FIGURA 3. Imagen tomada el 27 de julio de 2020 de la página de Facebook La Gaviota, https://www. facebook.com/AyGaviota/photos, /a.634005256634227/3194721350562592/

Angélica Rivera, exesposa del expresidente de México, Enrique Peña Nieto apareció entre los memes que circularon sobre el líquido de las rodillas. En 2014 Angélica Rivera estuvo involucrada en un escándalo de corrupción en el que periodistas y el equipo de investigación de Aristegui Noticias documentaron las relaciones que Enrique Peña Nieto sostenía con el Grupo Higa, una de las empresas que ganó varias licitaciones en su administración. En «La casa blanca de Enrique Peña Nieto», como nombraron al reportaje, se dio a conocer el valor de 7 millones de dólares que poseía la casa y, ante las críticas, Angélica Rivera apareció en cadena nacional reclamando la integridad de su familia y argumentando las supuestas fuentes de financiamiento de la casa escriturada a su nombre.

Entre los muchos escándalos de corrupción en el sexenio de Enrique Peña Nieto, este fue de los más sonados. En buena medida por las medidas de censura a Carmen Aristegui, periodista que dirigió el reportaje y que se vio confrontada legalmente con el grupo MVS Radio, con quienes colaboraba con un programa de radio. Los memes en esta tesitura nos recuerdan que la memoria, el humor y la política se combinan como una forma de crítica a las gobernanzas en México.

Bradley E. Wiggins (2019) argumenta que los memes de internet son un género de comunicación en línea que poseen un grado de crítica hacia un político, una celebridad o un problema social. Para este autor la gran mayoría de los memes críticos tienen una direccionalidad que aborda al menos dos grupos, uno que está posicionado para «entender el chiste» y uno que puede ser el objeto de la broma. Para este autor la práctica 
ideológica del meme parte en atender las prácticas de compartir, curar y mezclar. Wiggins señala que los memes de internet pueden ser el medio por el cual el público gana acceso a más información al fomentar el compromiso social (2019, p. 107). El argumento de Wiggins es pertinente para considerar la entextualización y montajes en estos medios visuales; sin embargo, ver el meme como medio para ganar acceso, me parece, continúa con una lectura representativa de la mediación.

Para una crítica de los usos instrumentales de los medios de comunicación, en este caso medios visuales, María José de Abreu (2019) ha argumentado que se debería pensar en el medio como una zona espacio-temporal que construye atmósferas y ritmos; digamos, el medio en momentos de crisis constituye intervalos regulares o umbrales para montar una realidad en un contínuum relacional. En esta pandemia, medios visuales como los memes alteran las formas de distinguir lo falso de lo verdadero, construyen atmósferas de humor insertas en el estado de ánimo de desconfianza. Este régimen de verdad también apuesta por el montaje y la circulación recombinante (Fattal, 2014). No obstante, a diferencia del régimen conformado por medios digitales y plataformas de verificación, en este régimen el humor es la bisagra que altera y produce valores, afectos, tensiones y exclusiones. Los videos que sujetos sociales (en este caso, familiares de personas hospitalizadas o fallecidas de covid-19) movilizan para denunciar, evidenciar y comprobar realidades son retomados en medios visuales para propiciar prácticas de discriminación, o bien para criticar la política mexicana. Estas prácticas se basan en el prolífico tropo visual de evidencia que se conforma por narrativas de muchos tipos, tanto de los medios de comunicación digitales, plataformas de verificación, memes y videos expuestos en redes sociales. La elaboración del tropo visual de evidencia gira en torno a una dialéctica de justicia y verdad en la historia mexicana relacionada con el poder de la legibilidad y legitimidad.

\section{El manejo de las impresiones}

Es de noche durante abril y Javier Alatorre, conductor del noticiario Hechos con Javier Alatorre, anunció: «No haga caso a Hugo López-Gatell». Este noticiario es transmitido por TV Azteca, la cadena televisiva que, junto con Televisa, disputan la hegemonía mediática en México. Javier Alatorre refirió que las cifras del subsecretario de Salud, Hugo López-Gatell, eran falsas. Desde el comienzo de la contingencia, López-Gatell ha sido el encargado oficial de externar las medidas sanitarias en México. El pronunciamiento de Javier Alatorre resonó fuertemente en redes sociales, al suscitar desde memes hasta posturas de periodistas, académicos y sociedad civil expresando su rechazo al conductor de noticias y pidiendo una 
disculpa a López-Gatell. Al día siguiente del pronunciamiento de Alatorre, en el informe diario sobre la covid-19 en México, uno de los periodistas alzó la mano y le preguntó a López-Gatell su opinión respecto a lo dicho por el conductor de noticias. El subsecretario de Salud dio una larga respuesta en la que argumentaba el honor de ser el portavoz del personal médico responsable en esta pandemia, pero en ningún momento aludió a Alatorre ni contradijo al conductor; se limitó en dar un recuento de las diferentes áreas involucradas que han permitido mitigar los fallecimientos $^{18}$. Por otra parte, diferentes medios de comunicación entrevistaron al presidente López Obrador sobre lo dicho por Alatorre y este inmediatamente señaló que su «amigo» Javier se equivocó. Sugirió que se atendieran las recomendaciones de personas especialistas, honestas y responsables como López-Gatell, y sostuvo que lo pronunciado por Javier Alatorre no fue algo bien pensado ${ }^{19}$.

Algo que llamó la atención en esta contingencia fue la personalidad de Hugo López-Gatell, el vocero y especialista que el gobierno de López Obrador encomendó con la tarea de transmitir la situación de la covid-19 en México. Su porte erguido, serio, discurso enfático, mirada contundente y sus respuestas precisas ante la prensa eran la contraparte del presidente López Obrador, que constantemente contradecía su discurso e incluso las medidas de salud indicadas por Gatell; su lenguaje verbal y no verbal lento, generalmente cargado con juicios valorativos, creaba cismas entre los medios de comunicación y el gobierno, o bien entre gobernadores de oposición ${ }^{20}$, empresarios y los diferentes grupos sociales ${ }^{21}$.

Ante la suma de contradicciones del presidente, la fachada de LópezGatell resonó como un artífice clave para, de alguna manera, conservar las expectativas que la Cuarta Transformación había creado para los mexicanos. El trabajo de Max Weber es fundamental para pensar la legitimidad

18 Ver en https://www.youtube.com/watch?v=ynRthqMGAec\&t=263s (canal de Saúl Munzer). Cabe destacar que muchos de los videos que revisé provienen de canales de usuarios que muestran una clara postura a favor de López-Gatell. Otro nicho interesante de análisis son las discusiones que resultan en los comentarios de videos en YouTube, la conformación de públicos o audiencias.

19 Ver en https://www.youtube.com/watch?v=ob5mfvWEB6o\&t=148s (canal de El Universal). 20 La «Alianza Federalista por México» está conformada por los gobernadores de los estados de Coahuila, Nuevo León, Tamaulipas, Durango, Michoacán, Colima, Jalisco, Guanajuato, Chihuahua, San Luis Potosí y Querétaro. Esta Alianza surgió en esta pandemia por políticos de oposición al partido político en turno, y exige al gobierno de López Obrador mayor apoyo económico ante la actual crisis económica.

21 Sobre esto último, López Obrador enfatizó que su gobierno era feminista; sin embargo, y pese al incremento de violencia contra las mujeres en confinamiento según cifras oficiales, el presidente aludió: «El 90\% de las llamadas de auxilio sobre violencia contra las mujeres son falsas». Ver en https://www.animalpolitico.com/2020/05/Ilamadas-falsas-violencia-mujeresamlo/ 
política junto con la dominación carismática, es decir, aquellas estrategias que los caudillos ejercen para mantener el control y legitimar el uso de la fuerza para la obtención de poder. López-Gatell ha construido un carisma ante los mexicanos, pero para ello ha sabido manejar sus impresiones. En este último apartado me interesa ver el carisma en pequeña escala, partiendo del modelo interaccionista de Erving Goffman (1997) al atender la presentación de Hugo López-Gatell en la vida cotidiana. El análisis de la performance de López-Gatell en su modalidad digital está ligado al análisis de la emoción histórica de la desconfianza al mostrar un diferente régimen de verdad. En México, al tener una gran circulación de información y de especulaciones ante esta pandemia, el discurso contradictorio del presidente y de conductores de noticias, la contienda entre cárteles al interior del país, y la crisis económica que se vive y se espera, los aspectos que López-Gatell proyecta son en suma el elemento constitutivo de la realización del poder político actual.

Dos días después del llamado a no hacer caso a Hugo López-Gatell, Javier Alatorre objetó su postura; de nuevo en cadena nacional dijo que lo pronunciado días antes se refería a las inconsistencias de los datos y de las cifras expedidas por el subsecretario de Salud ${ }^{22}$. Sostuvo que en ningún momento hizo un llamado a desobedecer las indicaciones del Consejo de Salubridad. Alatorre hizo uso de prácticas preventivas, las que Goffman caracteriza como: "Las técnicas empleadas para salvaguardar la impresión fomentada por un individuo durante su presencia ante otros» (1997, p. 25). Esta práctica preventiva, además de materializarse en su discurso, fue mostrada en la entrevista que hizo a López-Gatell ${ }^{23}$.

Para Goffman los gestos y las posturas no son acciones insignificantes, sino, al contrario, son signos cargados de significados que comunican a la audiencia que los observa. Este lenguaje, que puede ser pensado, a veces es realizado de manera inconsciente. Goffman argumenta que en la actuación de la persona existen deslices o disrupciones, los cuales dan cuenta de las inconsistencias en la acción social. Sin embargo, hay personas que ejecutan un muy buen papel, al manejar las impresiones de tal manera que controlan la situación.

22 Para este argumento, Javier Alatorre se apoyó en las críticas que el gobernador de Baja California, Jaime Bonilla, hizo a los «datos inconsistentes» de López-Gatell. Las tensiones entre Jaime Bonilla y el gobierno de López Obrador refieren que, en días antes del pronunciamiento de Alatorre, Jaime Bonilla decretó la «Ley Bonilla» para extender su mandato, porque en 2021 habrá elecciones en 15 estados del país, Baja California incluido. La Ley Bonilla fue invalidada por la Suprema Corte de Justicia de la Nación (SCJN) en mayo.

$23 \mathrm{Ver}$ en https://www.youtube.com/watch?v=uM1OrzB4gxs\&t=299s (canal de Saul Munzer). 
Hugo López-Gatell, sentado frente a Javier Alatorre, mantiene sus piernas abiertas mientras coloca las palmas de sus manos sobre sus rodillas. Gatell, atento a la pregunta de Alatorre, lo observa con seriedad, pero ¿qué es la seriedad en este contexto? Sin gesticular, sonreír o abrir la boca, casi sin parpadear, Gatell asiente a lo que indica Alatorre. No interrumpe o interviene mientras Alatorre habla: una práctica a destacar, un indicador que muestra la escucha atenta y ¿educada? de Gatell. Por esta práctica Gatell ha sido reconocido por periodistas, académicos y analistas políticos, al considerar que el subsecretario de Salud atiende preguntas no muy concretas o tal vez superficiales sin dar respuestas viscerales. López-Gatell, como político y figura pública, conoce que las proyecciones de su persona tienen un significado; esto se eleva por ser el vocero de una epidemia con gran alcance, de proximidad con las audiencias a través de las imágenes en la historia moderna y, además, poseer un discurso y terminología médica. En este sentido, como Goffman menciona, los otros, las audiencias, descubren que el individuo les ha informado acerca de lo que es y de lo que ellos deberían ver: doctor, figura pública, político que escucha atento sin intervenir.

En esta entrevista, Gatell enmarca sus respuestas sobre el proceso de notificación que los tres niveles de gobierno (local, estatal y federal) dan a la Secretaría de Salud Federal. Señala que en esta burocracia digital hay desfases y, por ende, las cifras varían al no actualizarse de manera inmediata. Pero detengámonos en la escucha atenta que Gatell guarda, manejo de impresión que se relaciona con el actuante disciplinado de Goffman, como un hombre que posee autocontrol: «El actuante disciplinado desde el punto de vista dramático es aquel que recuerda su parte y no hace gestos impensados ni da pasos en falso durante la actuación. Es un hombre prudente, que no traiciona la representación revelando involuntariamente sus secretos» (1997, p. 231). El timbre de voz fuerte y a una velocidad en la que podemos comprender su discurso, el movimiento de sus manos

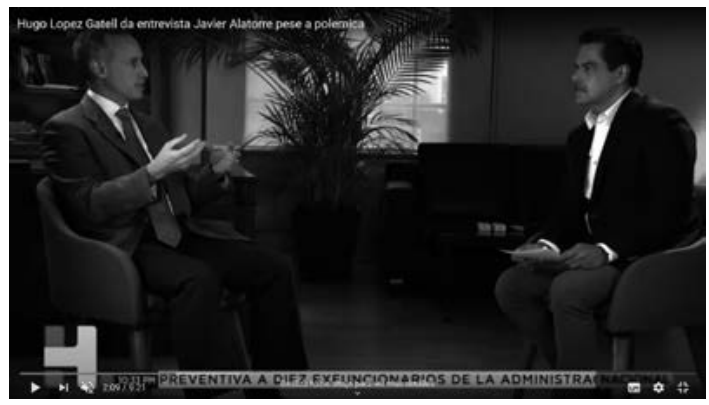

IMAGEN 4. Captura de pantalla de la entrevista en el canal de YouTube de Saul Munzer. 
colocadas a la altura del pecho, sin alzarlas, a una distancia corta para indicar con ellas que las palabras que señala son gestos de un autocontrol por parte de Hugo López-Gatell.

La intención de poner en escena la representación de un médico empático pero a la vez preciso, como Goffman menciona, no es algo orgánico que nace de la nada; su fundamento interno es propiciar «un efecto dramático que surge difusamente en la escena representada, y el problema característico, la preocupación decisiva es saber si le dará o no crédito» (1997, p. 269). Lo que he argumentado en este último y pequeño apartado es la fachada y presentación de Gatell ante las audiencias mexicanas. Más allá de adentrarme en aspectos psicológicos, quise mostrar los aspectos sociales como gestos y posturas que forman índices, y a su vez configuran signos de veracidad. La performance o actuación implica un reconocimiento y visibilidad. Sobre esto me parece pertinente preguntar cómo en el manejo soberano de las impresiones entre funcionario público y conductor de televisión se entrelaza la regulación patriarcal en la esfera pública. Si bien «el honor masculino fue la piedra angular en la construcción de una esfera pública moderna en México» (Piccato, 2015, p. 25), la forma en que se monta la escena por parte del conductor de noticias para interpelar a las audiencias e indicar a qué se tiene que hacer caso y a qué no, alude a la naturalidad en que los medios hegemónicos y la clase política en México construyen una matriz patriarcal en el espacio público y mediático. Esto apuntaría hacia un tipo de régimen de verdad a partir del uso soberano y patriarcal de las impresiones en México en la actual contingencia de salud.

\section{Consideraciones finales}

A lo largo de este ensayo reflexioné en torno a una emoción y un estado de ánimo de desconfianza que he sentido vibrar en la esfera pública a la que he tenido acceso en esta pandemia: internet y redes sociales. Mi interés fue mostrar que los signos siempre son resignificados y que en su reproducción y circulación se interrelaciona una cuestión de poder que tiene que ver con la regimentación de verdades para la obtención de visibilidad y presencia en la escena pública mexicana. Estos signos vistos a partir de imágenes, videos y memes son tecnologías y modos de comunicación que han circulado en esta pandemia para desencadenar desconfianza. Más que apostar por un relativismo (todo es verdadero) o un racionalismo (todo es falso), quise adentrarme en las composiciones que sujetos sociales construyen para dar forma a lo que conciben como verdad. No quise preguntarme por qué las personas creen en «noticias falsas»; más bien a partir de elementos heurísticos como el montaje me 
aproximé a los íconos, índices y símbolos que conforman la desconfianza en México.

Los regímenes de verdad que he analizado van desde el montaje que la plataforma de verificación de datos El Sabueso del medio digital Animal Político construye para desacreditar otros montajes; paradójicamente, estos últimos se basan en lenguajes hegemónicos de racionalidad. Otro régimen a considerar son los videos que familiares de personas hospitalizadas o fallecidas de covid-19 movilizan para denunciar, evidenciar y comprobar realidades. Estos videos son retomados en memes para propiciar prácticas de discriminación, o bien para criticar la gobernanza en México. Estas prácticas se basan en el tropo visual de evidencia que se conforma por narrativas de muchos tipos, y su elaboración gira en torno a una dialéctica de justicia y verdad relacionada con el poder de la legibilidad y legitimidad. Por último, otro régimen en el que ahondé fue sobre la puesta en escena entre el subsecretario de Salud, Hugo López-Gatell, y el conductor de noticias, Javier Alatorre. Intenté mostrar los aspectos sociales como gestos y posturas que forman índices, y a su vez configuran signos de veracidad, principalmente en el funcionario público. Pero también esta puesta en escena alude a la presencia patriarcal de los medios hegemónicos y de la clase política en México que dicta lo que se tiene que creer y lo que se debe rechazar.

Michel Foucault (1979) en Microfísica del poder argumentó: «La verdad está ligada circularmente a los sistemas de poder que la producen y la mantienen, y a los efectos de poder que induce y que la acompañan» $(1979$, p. 189). Para Foucault la economía política de la verdad está sometida por regímenes, aquellas formaciones producidas por el capitalismo en cada país. Así, para Foucault la verdad es en sí misma poder. Si continuara con esta misma lectura de atender la verdad como poder, me parece, no podría mostrar los tres tipos de composiciones que argumento. A diferencia de Foucault, entonces, considero que la verdad no es en sí misma poder, sino que la verdad como la violencia es un instrumento para detectar el poder. Los medios hegemónicos en México (Televisa y TV Azteca, y recientemente Grupo Imagen y Grupo Multimedios) han perdido legitimidad y predominio en la esfera pública mexicana desde que hemos conocido sus relaciones con grupos políticos en turno y desde el ascenso de medios, plataformas digitales y de las redes sociales a la escena pública. Si bien ya no predominan totalmente en la escena pública, tampoco están completamente desdibujados de ella como lo hemos visto en este texto. De tal manera, considero atender la verdad no como poder, sino como un proceso hegemónico en México. En tal proceso diferentes grupos sociales construyen regímenes de verdad para la obtención de poder, visto 
este a partir de la legitimidad y la legibilidad. Los regímenes muestran su materialidad en el video e imágenes que circulan en la nombrada era de la «posverdad», atravesada ahora por un virus que vino a configurar y a poner en diálogo nuevas y viejas prácticas comunicativas. Tal proceso entonces debería comprenderse como histórico, contradictorio, jamás completo y siempre en constante emergencia.

Mi preocupación aquí entonces radica en la generación de más preguntas en torno no de los medios de comunicación en sí mismos, sino de un modo de gobierno entre medios de comunicación y clase política (De Abreu, 2019), para producir atmósferas cargadas de veracidad en una sociedad como la mexicana, en medio de una contingencia sanitaria donde prima un estado de ánimo de desconfianza. Y en el alcance de la investigación antropológica, particularmente en la región latinoamericana sobre los cambios en las dinámicas virtuales para reflexionar las diferentes prácticas de crítica política, diferenciación y exclusión que se entrelazan.

\section{Contribuciones}

Andrea Murillo ha participado en la concepción, la recolección de datos, la redacción y la aprobación de la versión final del artículo. La autora agradece la lectura atenta y generosa de Gabriela Zamorano a los dos primeros borradores de este ensayo, y las valiosas sugerencias editoriales de la revista, así como el intercambio epistemológico, siempre emocionante, con Laura Lee Roush.

\section{Fuentes de financiamiento}

Este trabajo fue financiado por la beca de manutención que el Consejo Nacional de Ciencia y Tecnología (Conacyt) brinda a estudiantes de posgrado, nivel doctorado, a través de El Colegio de Michoacán.

\section{Conflictos de interés}

Ninguno. 


\section{REFERENCIAS BIBLIOGRÁFICAS}

Bajtín, M. (1989). Teoría y estética de la novela. Trabajos de investigación. Madrid:Taurus.

Boyer, D. (2010). Digital expertise in online journalism (and anthropology). Anthropological Quarterly, Anthropological Perspectives in the Digital Age, 83(1), pp. 73-95. DOI: 10.1353/anq.0.0114

Briggs, C. (2004). Theorizing modernity conspiratorially: science, scale, and the political economy of public discourse in explanations of a cholera epidemic. American Ethnologist, 31(2), pp. 164-187. DOI: 10.1525/ ae.2004.31.2.164

Carlson, J. y Stewart, K. (2014). The legibilities of mood work. New Formations, 82(7), pp. 114-133. DOI: 10.3898/NEWF.82.07.2014

Carrión, L. (2018). La fosa del agua. Desapariciones y feminicidios en el río de los Remedios. Ciudad de México: Penguin Random House.

De Abreu, M. J. (2019). Medium theory; or, «The War of the Worlds» at regular intervals. Current Anthropology, 60(5), s. p. DOI: https://doi. org/10.1086/705345

De la Cadena, M. (2014). El racismo silencioso y la superioridad de los intelectuales en el Perú. En C. Hünefeldt, M. de la Cadena y C. Méndez, Racismo y etnicidad (pp. 54-97). Lima: Ministerio de Cultura.

Deleuze, G. (1987). El bergsonismo. Madrid: Cátedra y Colección Teorema.

Edwards, J., Harvey, P. y Wade, P. (2010). Technologized images, technologized bodies. Nueva York y Oxford: Berghahn books.

Fattal, A. (2014). Hostile remixes on YouTube: A new constraint on proFARC counterpublics in Colombia. American Ethnologist, 41(2), pp. 320335. DOI: 10.1111/amet.12078

Foucault, M. (1979). Microfísica del poder. Madrid: Ediciones La Piqueta.

Gallagher, E. (2017). Mexico: articles about bots \& trolls. Medium. Recuperado de https://medium.com/@erin_gallagher/news-articles-about-botstrolls-in-mexican-networks-7b1e551ef4a6

Goffman, E. (1997). La presentación de la persona en la vida cotidiana. Buenos Aires: Amorrortu Editores.

Graan, A. (2018). The fake news mills of Macedonia and other liberal panics. Cultural Anthropology. Recuperado de https://culanth.org/fieldsights/thefake-news-mills-of-macedonia-and-other-liberal-panics-1

Habermas, J. (1981). Historia y crítica de la opinión pública. La transformación estructural de la vida pública. Barcelona: Gustavo Gili. 
Hirschkind, C., De Abreu, M. J. y Caduff, C. (2017). New media, new publics? An introduction to supplement. Current Anthropology, 58(15), pp. 3-12. DOI: $10.1086 / 688903$

Johnson, J. (2018). The self-radicalization of white men: «Fake news» and the affective networking of paranoia. Communication Culture \& Critique, 11(1), pp. 100-115. DOl: https://doi.org/10.1093/ccc/tcx014

Koselleck, R. (1993). Futuro pasado: para una semántica de los tiempos históricos. Barcelona: Paidós.

Lepselter, S. (2016). The resonance of unseen things poetics, power, captivity, and UFOs in the American Uncanny. Michigan: University of Michigan Press.

Piccato, P. (2015). La tiranía de la opinión. El honor en la construcción de la esfera pública en México. Ciudad de México: El Colegio de Michoacán y El Instituto Mora.

Piccato, P. (2017). A history of infamy. Crime, truth, and justice in Mexico. Oakland: University of California Press.

Reguillo, R. (2011). Lo análogo en el periodismo digital. Letras Libres. Recuperado de https://www.letraslibres.com/mexico/lo-analogo-en-el-periodismo-digital

Reguillo, R. (junio, 2020). Cartografías digitales: metodologías para tiempos nuevos. Trabajo presentado en el ciclo de videoconferencias Antropología en confinamiento. Alternativas etnográficas y trabajo de campo durante la pandemia, organizado por el Centro de Investigaciones y Estudios Superiores en Antropología Social, CIESAS.

Stewart, K. (2014). Tactile compositions. En P. Harvey, E. C. Casella, G. Evans, H. Knox, C. McLean, E. Silva, N. Thoburn y K. Woodward, K. (Eds.), Objects and Materials (pp. 119-127). Londres: Routledge.

Wiggins, B. (2019). The discursive power of memes in digital culture. Ideology, Semiotics and Intertextuality. Londres: Routledge.

Zamorano, G. (2018). An expected revolution? Visuality, autodefensas, and imaginaries of citizens' self-protection in Mexico. Anthrovision, 6(2), pp. 1-22. DOI: https://doi.org/10.4000/anthrovision.3861

Zamorano, G. (2020). Efectos de ciudadanía: nuevos archivos digitales y la formación de contrapúblicos en el contexto de violencia de Michoacán, México. En prensa. 